\title{
A Comparative Proposal on Learning the Chaos to Understand the Environment
}

\author{
Mustafa Atilla Arıcıoğlu (iD *,1 and Osman Nurullah Berk iD $\beta, 2$ \\ ${ }^{*}$ Department of Business, Faculty of Political Science, Necmettin Erbakan University, 42090, Konya, Turkey, ${ }^{\beta}$ Department of Business, Beysehir Ali Akkanat \\ Faculty of Business Administration, Selcuk University, 42130, Konya, Turkey.
}

ABSTRACT Towards the end of the twentieth century, radical changes have taken place within the framework of strategic management and organization-environment relationship. Technology, speed, competition and globalization factors have rapidly modified the environmental dynamics in the organization-environment relationship. In today's chaotic world, the effects of the crisis and environmental uncertainties have spread rapidly and widely not only in narrow area but all over the world. This situation makes it difficult for organizations aiming to live an eternal life to continue their lives and accelerates the occurrence of organizational death. In this context, Organizational Ecology and Chaos Theories have been emerging as guides in ensuring the sustainability of organizations. This study, it is aimed to draw a road map for organizations by making a comparison based on the suggestions and arguments of Organizational Ecology and Chaos Theories in order for organizations to have a more sustainable life. As a result of the evaluation, recommendations were made for learning to live with uncertainties and a correct action plan by developing sensors on the way to becoming a sustainable organization, based on the dynamics of the future. At this point, organizations need to have a flexible and agile structure and develop early warning systems so that they can leave the foggy and unpredictable environment created by the chaotic atmosphere with minimum damage and seize the new opportunities that arise. In addition, they should determine strategies by developing various scenarios against unforeseen threats, and they should consider environmental factors while doing these.

\section{INTRODUCTION}

Discussions on the existence and sustainability of organizations have been one of the most significant areas for organizational theories. Identifying the organization by themselves or describing the notions of competition, environment, employees and processes by the administrators on the basis of the organization have been reviewed in the context of the environment in post-modernist approaches in addition to the modern organizational theory approaches. This ancient relationship between the organization and the environment has become even more striking since the end of the 1980s.

As a matter of fact, the shaping of the new world by globalization indicates the existence of a process that needs to be fol-

Manuscript received: 20 September 2021,

Revised: 8 November 2021,

Accepted: 31 December 2021.

1 maaricioglu@erbakan.edu.tr

2 osman.berk@selcuk.edu.tr (Corresponding Author)
KEYWORDS

Chaos

Organizational

ecology

Environment

Sustainability lowed more carefully for organizations. Economic, political and legal changes deal with new actors, new dynamism and new / reemerging concepts within this process.

In other words, it will be possible for organizations to understand the environment by learning these changes. The vision of the manager and the internal dynamics of the organizations become more important in this effort to make sense. Because the world has become more interconnected and dependent than ever before by adapting to technology with its contents. The reason for the mutual fragilities in the international arena to gain a new dimension is based on global and technological developments (Kotler and Caslione 2009). However, the developments experienced have led to some negative changes in people's lives as well as positive developments. Increasing interaction between countries and people, the changing permeability between societies, the increasing importance of companies in world management, companies' competitive tools becoming insufficient for consumers/customers, the continuation of discussions about what the existence of humans is 
or how affect the environment makes it difficult for organizations to understand the environment and even more their impacts on the environment.

These waves of change and transformation affect organizations significantly and lead to unexpected results. In today's world, sudden and rapid changes can occur in a short time that can lead to unexpected results. This situation can unexpectedly change the value phenomenon of organizations that are in constant interaction with their environment, and can overturn the advantages of the market. All these developments have revealed the necessity for organizations to adapt to a complex, chaotic and dynamic environment in order to maintain their sustainability and gain a competitive advantage in today's world (Stacey et al. 2000). This situation includes the emphasis on the period that Van-Eijnatten wrote alone in 2004 (van Eijnatten 2004), with other colleagues in 2002 and 2004 (Fitzgerald and van Eijnatten 2002; van Eijnatten and Putnik 2004). The authors mark a new century that begins with uncertainty, high mobility, speed, turbulence and vulnerabilities. Chaos will speak of itself as a new context for understanding this century. In other words, chaos will be the new guide and instructor of organizations in understanding the environment and organizational learning. However, for this reason, the meaning that the environment and the organization will attribute to chaos in order to learn itself appears as another important context.

\section{LITERATURE VIEW}

Contemporary management theories take into account the rapid changes in today's organizational environment and help to understand, interpret and explain the impact of changes on organizations (Porth and McCall 2001). In the literature, while many contemporary management theories such as resource-based theory, agency theory, institutional theory, contingency theory and systems theory are discussed in depth within the framework of the organization, it is seen that organizational ecology, chaos and theory are not examined in an integrated way. Organizational ecology and chaos theories are still difficult to understand and apply in contemporary organizations. In this study, it is aimed to make it easier to understand and apply these two theories in an integrated way by discussing them in depth and comparatively. When the studies conducted in recent years are examined, it is observed that there is an increase in research on chaos and organizational ecology theories in different application areas and different organizational forms. The studies conducted are listed below in chronological order.

Thietart and Forgues (1995) that deals with the theories of chaos and organization together, it is stated that the processes related to the management of organizations are actually included in the preferences and are embedded in the processes. The researchers, who went through 6 principles in the studies on the chaotic field, concluded that "similar actions should never lead to the same result during a single institutional lifetime or between two different organizations". Bayramoğlu (2016) emphasizes what needs to be done in order to gain a perspective and approach, based on the assumption that, despite the increasing number of studies on chaos, it is complex and does not have the desired competence in examining the relationship between chaos and organization theories. It is argued that this acquisition gains importance in ensuring success and that the chaos and complexity paradigm should be considered in this context. In another study dealing with chaos and organization theories, the topics of governance in projects, organizational design and governmentality were examined (Simard et al. 2018). In this research, a conceptual framework has been developed showing that governance, organizational design and managerialism are necessary for understanding projects. The paper offers a theoretical contribution to project studies by creating a bridge between process theory, the sensemaking perspective and the study of organizational project management.

Researchers have comparatively examined the theories of chaos, complexity and contingency in order for organizations to cope with the difficulties with the changes that have emerged with globalization and technological developments in the 21st century, the change in the nature of competition and the increase in unpredictable events. Looking at the concepts used for chaos; nonlinearity, feedback, bifurcation, odd attractors, fractals, self-organization for complexity theory; for the theory of non-linearity, dynamism, feedback, self-organization, emergence, and contingency; coherence, equifinality, effectiveness, and relevance were used. After all; inferences were put forward by comparing the working examples of the examined theories with their organizational applications (Lartey et al. 2020). Eight organizational theories related to supply chain management and their possible future research questions are identified and explained in the research (Prakash et al. 2020), which examines how humanitarian organizations should follow a path for their supply chain. Of these, the first four theories (i.e. resourcebased theory, resource dependency theory, social exchange theory, and contingency theory) were initially applied in the humanitarian field, while the remaining theories (i.e., institutional theory, stakeholder theory, transactional cost theory, and information theory) have the potential to be applied in the future. In the context of creating and managing strategies for businesses, Arıcıoglu et al. (2021) scanned the studies on chaos and selected the ones which are suitable for the purpose. They presented a short proposal title stating the importance of chaos for strategic management and how it guides managers. Using the propositions of chaos theory as an inclusive approach, Altinay and Arici (2021) evaluated the changing marketing channels in organizations providing accommodation service after the COVID-19 outbreak.

\section{ORGANIZATIONAL ECOLOGY AND CHAOS ON LEARNING THE ENVIRONMENT DURING THE LIFE OF THE ORGANI- ZATION}

Mankind acquired many things from nature in his relationship with the environment, but he uses it against nature. This exploitation isn't a new phenomenon (Adorno and Horkheimer 2010). On the other hand, learning to live with it by understanding the environment also has the same history as an awareness (Habermas and Kanat 1997).

Handling this relationship within the context of the organization does not depend on a very different perception and context. When associating Taylor's organization with the environment or explaining the existence of open system theory through the environment, the context in question is on this distinction: living together or using nature. However, the priority in both situations is learning the environment. For this reason, the definition and understanding of the environment are decisive. This is the subject that organizational theories also insist on.

One of the most interesting approaches on this subject stands out as Organizational Ecology and the other as Chaos Theory. The efforts for both of them to understand and define the environment actually bring with it the effort to define and understand the organization as well. 
If the Organizational Ecology Theory is dealt with first, the two main issues that the theory seeks to answer are; the reasons for the existence of organizations and the different characteristics of organizations (Leblebici 2004). In ontological justification within these two issues; the understanding of order and universe explained with Newton's determinism leaves its place to regular chaos and differences are explained with fractal geometry (Poincaré and Maitland 2003; Chamberlain 1995; Moran 2018).

On the other hand, Organizational Ecology theory explains itself through three propositions by considering the relations between organization and environment (Baum 1999):

- Organizations are dynamic and new forms of organization emerge. However, these organizations live as much as the environment allows.

- Difficulties arise for organizations to respond to an uncertain and changing environment.

- There are differences and diversity in organizations in terms of their internal structures. On the other hand, it exists on three basic principles proposed for Chaos Theory.

- The reason for organizational mobility is complex movements related to human activities and human mobility in the environment.

- Organizations, as an open system, are naturally exposed to the effect of the environment and affected by these.

- The reactions of organizations affect their internal structures as much as they affect the environment.

Both theories advocate the importance of the environment and there is no one-way result in the interaction of the organization and environment.

On the other hand, Ecology Theory associates the survival of such species with evolution and states that diversification and reproduction occur during the evolutionary process (Leblebici 2004). Various opinions and thoughts have been put forward on the environment and environmental formation from past to present. The theories of Lamarck (1744-1829) and Darwin (1809-1882), which have an evolutionary perspective, form the basis of these. According to Lamarck, every being is formed according to the physical conditions in which it exists and it has to adapt to these physical conditions. Lamarck claims that living things create organs according to their needs, and that if they are not needed, these organs disappear by blunting over time. The transmission of these traits genetically to future individuals inherited has raised a number of unanswerable questions, and at this point, Darwin supported Lamarck's assumptions of genetical gravity and adaptation to the environment with a more scientific approach, with the findings of natural selection and survival. Darwin argues that living things can remain strong throughout their lives only by natural selection (Grandinetti 2018). He also argued that in order for living species to have a sustainable life, they must first show diversity and then adapt to the environment. The change that Darwin has mentioned at this point may be necessary according to the changing environmental conditions (Mayr 1972; Hancerlioglu 1995). As a matter of fact, ecology in a general expression states that organizations change in order to adapt to the changes in the environment and as a result of this change, there is a diversification in the organizations, as a result of this diversification, some organizations are chosen by the environment and are kept alive. It can be said that this point of view is the result of handling the life processes of organizations in a similar way to living things. Within this context, the theory focuses on the selection, survival, legitimacy and death of organizations. The theory focuses on organizational popula- tions and communities rather than on an organization by making macro-scale explanations (?).

An important issue in theory is the process of change that causes diversification. Researchers have different views on the causes of change. In general terms, these are discussed under two headings as internal and external causes (Baum 1999). Political, legal, technical and institutional environment refers to external causes, while the interests of the organization, value judgments and degrees of dependency express internal causes. Another concept that draws attention to change is structural inertia, which refers to the unwilling stance and cumbersome structure of organizations against change. It is used to emphasize that organizations generally have a lower rate of change than the rate of change of the environment (Hannan and Freeman 1977). Hannan and Freeman advocate that the organization-environment relationship should be viewed from the perspective of environmental selection. Organizational ecology also pays attention to organizational features, but emphasizes the inherent organizational features that shape institutional environments and determine how specific organizations will respond to them. These include the cost of organizing, flexibility and stability or fragility (Abbott et al. 2016).

Another issue that has an important place in theory is organizational death and birth. Although there is no consensus on this issue, the entry of an organization into a new population is expressed as birth and exit from the population as death. Organizational deaths and births are important indicators in determining the characteristics (dynamics) of a population, that is, the organizational community formed by interacting organizations. Issues such as the total number of organizations in the population and the carrying capacity of the population, together with the death and birth rates, allow the determination of population dynamics (Baum and Oliver 1991). The basic view of Organizational Ecology theory is to understand the forces that shape organizational structures over the time span (Hannan and Freeman 1989).

Nevertheless, organizations, which are open systems, need to be able to respond quickly and rationally in this chaotic environment in order to survive the reactions from their environment. Otherwise, they will not be able to adapt to the changing conditions of the environment and will end their existence. Within this context, the environment that organizations are in is of great importance for organizations to survive this wind of change and ensure their sustainability. It is inevitable for organizations in terms of their sustainability to understand and correctly interpret ecology, which affects their activities and has an important effect on determining their lifespan. The key to survival for organizations, as in natural systems, is to develop rules that can keep an organization operating "on the brink of chaos" (Stacey et al. 2000).

The origin of modern chaos theory can be traced back to Hegel, Marx, and Engels, whose work focuses on historical evolution through dialectical processes between the opposing forces of stasis and change (Loye and Eisler 1987; Farazmand 2003). Henri Poincaré, who later noticed and became famous in the world, solved the problem of "three bodies", which was put forward on the stability of the solar system in 1889 , causing the term "chaos" to be used for the first time in a technical sense. Poincare laid the foundations of the chaos theory in New Science by proving that the solution of the solar system is sensitive to initial conditions and that the solar system can never be predicted whether it is stable or not because it is impossible to know the initial conditions of the universe (Gleick 1997). It was Lorenz who made Poincaré famous again. While forecasting the weather, as a result of his entry into the system by simplifying a number of sequences obtained 
from previous research results, Lorenz realized that the results that appeared in the chart created a different table than the previous ones, while waiting to receive the same results. Lorenz's expectation is the way that a difference of one thousand unity $(1 / 1000)$ created when entering sequences into the system will not affect the result. But this small change at the beginning affected the forecasts, and unlike the previous results, a bumpy, butterfly-like graph emerged (Gleick 2005). This revealed the "butterfly effect", which shows sensitivity to the initial state and forms the basis of Chaos Theory. Lorenz's results, by defining chaos as "a system with a uniform geometric structure that behaves randomly", emphasized that there is a "orderly disorder" in the system (Lorenz 1963). It is observed that small differences in variables can produce surprising results that cannot be predicted at the starting point. At this point Lorenz introduced two main features of the chaos theory. These; the principles of "Sensitive Dependence on Initial Conditions " and "Randomness" (Gleick 2005).

The general characteristic of chaos theory is that it is the "edge of chaos", which is defined as "the space in which the complex system spontaneously forms, adapts, and is alive", resulting from the fact that life stands between order and disorder (Heylighen 1999; Mitchell 1999).

Understanding and predicting practice and finding the exact practical equivalent of theories are some of the main goals of the theory. For this purpose, chaos theory has made an ontological differentiation in order to eliminate the deficiency in existing theories and evaluated the "disorder" situation from a different perspective (Aricioglu and Karabiyik 2019).

In this context, the following propositions summarize the chaos theory (Rockier 1991):

- Chaos theory helps to explain the nonlinear aspects of the universe.

- Combines the determinism of the Newtonian model with the randomness of quantum physics. It explains this partly through the concept of "strange attractors".

- Chaos theory shows that small changes in the beginning of a system can eventually lead to large differences.

- Understanding chaos leads us a perspective in which the universe is an open system.

- Human systems can be best explained by chaos theory. The nature of the human body and weather forecast are examples of this.

- It has a geometrically fractal structure (Fern).

- It has an original structure. No event repeats the same way (Snowflake).

- It can be stable (regular, cosmotic) within its own chaotic limits.

- It is not possible to be foreseen. Although it has a unique order, it also has an ambiguous side.

Chaos is not disorder; it represents the unpredictability of an evolutionary order system. Chaos Theory examines dynamical systems characterized by nonlinear, complex interactions and dynamic evolution over time (Levy 1994). It suggests that a small change in the initial condition of a nonlinear dynamic system can lead to unexpected results and makes it difficult to predict dynamical systems (Holmes 1995).

When the propositions of chaos are interpreted in the context of the organization-environment relationship; Small variables occurring in the system can bring unforeseen threats from the environment, which is an open system, and this can lead us to unexpected and effective results. This disorder has a unique and fragile structure and is not expected to be repeated. This whole range of uncertainty has an order in itself. In this context, being able to understand and respond to the organizational environment dominated by a regular disorder, to respond towards this and to develop sensors and to have a flexible structure are key to sustainability.

\section{A PROPOSITION ABOUT THE FUTURE OF THE ENVIRON- MENT}

The report "Global Trends 2025", published by the US National Intelligence Council in 2008, predicts that in the future, chaos, violence and upheaval will dominate the world (Global Trends 2025: A Transformed World 2008). In today's world, where everything is so dependent and fragile, predictions have been realized, and the situation of uncertainty affects all stakeholders living on earth. There are a number of factors that trigger and accelerate disorder, uncertainty, chaos, and change. These factors are briefly described below.

Globalization: One of the most important phenomena of change is globalization, accompanied by regionalization (the European, American and Asian blocks) and fragmentation (the Soviet Union and Yugoslavia). What is meant by globalization is that most states in the world belong to a system with global interaction (Mannermaa 2009). Globalization is actually the result of a logical process. Human history shows that human systems tend to create new, technological, economic and socio-political levels of systems throughout the development process. Development from self-contained village communities to city-states, nation-states, regional systems is a natural process of systematic development. The characteristic of this development is that the birth of a new level of system means an increase in the complexity of the entire system. The removal of borders, the increase of mobility and the level of interaction have changed the existing world order and led to the birth of a chaotic environment. One of the most important features of the international system since the Cold War, globalization is not a process of chaotic ending that brought only chaos occurring around in the states, but completely covering and affecting the global environment have been turned into an event that is. There is a great similarity between the properties of the chaotic structure described in chaos theory and the properties of the concept of globalization.

Technological Developments and The Information Revolution: Information Technologies, one of the main elements of the globalization revolution, are the biggest element shaping the new global economy. The emergence of a single platform that brings together, connects individuals, organizations and objects, it has led to the change of many phenomena from the way individuals and organizations work to the way they work, logistics, production, communication, consumption, etc. In addition to the positive effects of this change, there are a number of negative effects. Removing borders, making access to information so easy, and thus the emergence of big data, in other words, overloading information, and therefore causing more confusion and chaos (Kotler and Caslione 2009).

Extreme Competition: The constant development and change of technological developments have made it difficult for organizations to have a sustainable competitive advantage and has led to the formation of a difficult competitive environment. In order to survive in markets where intense and fast competitive moves are made, current developments and competitors must be carefully followed and the counter move must be made in a timely and accurate manner. Globalization, attractive substitute goods, changing 
consumer preferences and the emergence of new business models determine the pace of market disruptions in an intensely competitive environment. In order to resist competition in a chaotic environment, strategic foresight should be developed by organizational managers, importance should be given to the speed factor, and outsourcing and similar cooperation models should be implemented (Doherty and Delener 2001; D'aveni 2010).

\section{Changing Balances in the World (The Rise of the Rest of the}

World): The phenomenon of power from an economic and political point of view is constantly changing from the past to the present. The role of countries in the global market may vary depending on this situation. A process is underway in which the United States and the European Union are increasingly losing their sovereign roles, money and power are transferred to nations rich in natural resources, to developing countries. The 2008 financial crisis, Brexit, the Covid-19 pandemic, etc. events reveal and accelerate the course of change.

Power is shifting for the third time in the history of the Modern world (Zakaria 2013). The agricultural and industrial revolution in the 15th century, the rise of the USA in the 19th century, and thirdly, the change and development of China and Asian countries today can be explained in this way. BRICS countries, the RCEP agreement (Regional Comprehensive Economic Partnership) and wealthy Middle Eastern countries show us the "rise of the rest of the world" as new rising powers in the perspective of chaos and turmoil (Time, 2020). In this context, today, when fragility and uncertainty are at the line stage, as a result of the power changes occurring between countries, an environment of chaos occurs throughout the global world. Organizations as well as countries should strategically evaluate the opportunities and threats that may arise.

\section{CONCLUSION}

"Turbulence" occurs anywhere or at any time when the number of triggers increases and reaches high levels, as can be seen in the process that started before the 2008 crisis and is still ongoing. Organizations that have an agile and flexible organizational structure, early warning systems and can remain vigilant will be able to notice the turmoil. Some turbulence can only be noticed when chaos manifests itself. When chaos is underestimated, it can be difficult to exploit strategies that will protect the organization from the weaknesses caused by chaos or allow it to seize the opportunities it creates (Kotler and Caslione 2009). For this reason, it is important that organizations are always on guard against a possible state of chaos that may occur at any time in terms of sustainability of the organization and minimizing the damage that may occur. The organizational environment should be well analyzed, the phenomenon of change and development should be understood by the entire organization and become part of the organizational culture.

Understanding the environment in this context, despite their different philosophical backgrounds, two similar theories, with their insistence on learning, their belief in sustainability and their increasing consistency, contribute to understanding the environment around the following differences:

In order for organizations to understand the environment, they need to understand chaos by prioritizing it, applying propositions carefully in context, and developing a number of strategies. Within the framework of the propositions of the theories, a number of strategies for organization sustainability are presented below, especially to learn to live in chaos:

Flexibility and agility: Physically, structures should be able to stretch when the ground swings. A similar situation applies to organizations competing in today's turbulent environment. Organizations that can predict market movements best, re-emerge from the worst system shocks and take advantage of the gaps left by those who cannot withstand the impact will win (Economist 2009). For most organizations, the path to organizational agility is through transformation, reducing inefficiency, and the ability to reorganize around core values. Basic processes need to be optimized. It is important for the organization to act in a flexible structure so that information system closed to outside/communication are maximized, the alignment of basic information sharing processes and become standardized. At this point, care should be taken not to disrupt communication and teamwork.

Development of an early warning system: It is known that the turbulence can come at any time, from anywhere, some can be detected in advance, and some cannot. The detected turbulence should be analysed by the organization, and then the opportunities and weaknesses that may arise should be identified. In this way, these deficiencies can be minimized or eliminated completely. If we liken the organization to a passenger plane preparing for flight, it can be used to direct pre-flight air traffic, weather, traffic, etc. we can say that the "tower" is the organization's early warning system, which allows the Prevention of disruptions caused by environmental factors. They can prevent disasters that may occur by developing an early warning system that acts as a tower in airports while performing their activities in organizations.

Another factor to consider in the early warning system is the external environment in which the organization operates. In some cases, organizations can ignore the external environment by focusing on internal factors. According to Gilad, this situation is called "mismatch in the sector" and occurs during periods when market realities exceed the strategy of the organization. In order to cope with this situation, organizations must identify, monitor risks and take the necessary measures by management (Gilad 2003).

Developing scenarios: The main element of a strategy in chaos management is the development of scenarios that the organization will likely encounter by bringing together the ideas of managers, experts and stakeholders at the head of all units of the organization's managers. Preparing different scenarios, including the worst, expected and best, is important in terms of first response to a possible threat from the environment and reducing damage. Developing scenarios can simultaneously benefit the organization. It allows you to manage, measure and classify uncertainty. It allows to reduce confusion and separate what is really unknown and really important. It creates a clear structure that will be used when working on options to overcome a number of possible outcomes, and avoids regrets (Hirt et al. 2020).

Chaos theory sets out various scenarios for understanding and predicting organizational behaviour and system evolution. Both computer simulations and experimental studies are needed to determine characteristics and strategic inferences in the organizational environment. Due to the sensitivity property of chaos systems, the selected variable must be measured precisely (Doherty and Delener 2001). In the research conducted, four different levels of uncertainty states are separated from each other. Level one has a foreseeable future and develops a single scenario. The second level develops a small number of scenarios and predicts the probability that each scenario will be implemented. The third level develops a number of scenarios due to the complexity of the underlying factors. It is impossible to make a prediction with certainty when there will be real ambiguity, and decisions are made at that moment by intuition. This can be considered Level Four. It 
Table 1 Comparison of Organizational Ecology and Chaos Theories.

\begin{tabular}{|c|c|c|}
\hline Elements & Organizational Ecology & Chaos \\
\hline Background & $\begin{array}{l}\text { Mutation that allowed Darwin and Lamarck to cling } \\
\text { to the environment through }\end{array}$ & Anarchism or balance in disorder \\
\hline Time/Period & $\begin{array}{l}\text { Creating organizational characteristics of short-term } \\
\text { processes over a wide period of time in the evolutionary process }\end{array}$ & $\begin{array}{l}\text { An uncertain broad time or } \\
\text { beyond future time }\end{array}$ \\
\hline Motion/ Kinesis & Physical & Metaphysical \\
\hline $\begin{array}{l}\text { Making sense of } \\
\text { the environment }\end{array}$ & Competitive understanding & Existence of requirement for entity \\
\hline Competitions & High competition & Balancing \\
\hline Actors & Company / actor oriented & Governance approach \\
\hline Sustainability & Competitive and adaptable & $\begin{array}{l}\text { When life is learned with } \\
\text { the environment }\end{array}$ \\
\hline
\end{tabular}

is impossible to establish a relationship because it constantly shifts the relationship between cause and effect. Atmosphere of chaos caused by the Covid-19 pandemic in global markets can qualify as a level 4 .

Choice of scenario and strategy: In a world of extreme uncertainty, it will not be right in the long run to devise a strict, decisive plan. But making everything flexible in its entirety is also an expensive way, and may not achieve any of the organization's goals. Instead, a portfolio of strategic moves (scenarios) should be created that will collectively perform well in all possible scenarios, even if each scenario does not have a way out on its own.

After developing the most important scenarios, organization managers need to choose the most likely one from them. For each scenario, the optimal strategy must be found. Managers want to accept a strategy that coincides with a risk they are willing to take and as many opportunities as they want to evaluate. It is necessary to take into account the worst-case scenario and implement the strategy that will benefit the organization when the worst case occurs. This means minimizing maximum risk and is referred to in the literature as a mini-max strategy (Kotler and Caslione 2009). It is not possible to create a clear guide for scenario and strategy selection. Managers may want to take advantage of past experience, be timid/bold about taking risks, or argue that a scenario that mentions the existence of many opportunities may be the right choice. It is important to know that there are many unknowns, which scenario choice will be the right decision, as well as to be prepared for any turbulence and uncertainty that may occur.

Organizations should develop the capabilities, systems and processes to quickly identify and predict the upheavals that may arise in the environment in which they operate, identify their weaknesses, know and focus on their own values. It should be able to separate from the foggy and unpredictable environment created by the chaotic atmosphere with minimal damage and evaluate new opportunities that arise. In order to do this, they must constantly consider the environmental factor and take care of his relations with the environment. Considering that all uncertainties can come from the environment, the key to countering competition, reducing risk factors, following new developments in the market and ensuring the sustainability of the organization is to understand and analyze the environment in a good way. In order to predict any threat that may come from the environment, it is necessary to develop strategies and scenarios, evaluate opportunities, and teach managers and the organization to live with chaos as it does today. When these scenarios and strategies are understood by the entire organization, become part of everyday decision-making processes and are adopted in the organization as a culture, an organizational structure that chaos cannot shake arises. Organizations that have such an organizational structure will be able to live a sustainable life despite all the turmoil in today's world of chaos, where uncertainty increases every day and it becomes difficult to predict the future at any moment.

\section{Conflicts of interest}

The authors declare that there is no conflict of interest regarding the publication of this paper.

\section{Availability of data and material}

Not applicable. 


\section{LITERATURE CITED}

Abbott, K. W., J. F. Green, and R. O. Keohane, 2016 Organizational ecology and institutional change in global governance. International Organization 70: 247-277.

Adorno, T. W. and M. Horkheimer, 2010 Aydınlanmanın diyalektiği: felsefi fragmanlar. Kabalcı Yayınları, çev: Oğuz Özügül 1.

Altinay, L. and H. E. Arici, 2021 Transformation of the hospitality services marketing structure: a chaos theory perspective. Journal of Services Marketing .

Arıcıoğlu, M. A., B. Erer, and N. Gülnar, 2021 A known innovation for strategy: A study on chaos. In Financial Strategies in Competitive Markets, pp. 179-191, Springer.

Aricioglu, M. A. and H. Ç. Karabiyik, 2019 Örgütlerin geleceğine bir önerme olarak kaos teorisi ve kaos olgusunu anlamak. Medeniyet ve Toplum Dergisi 3: 145-156.

Baum, J. A., 1999 Organizational ecology. Studying organization: Theory and method pp. 71-108.

Baum, J. A. and C. Oliver, 1991 Institutional linkages and organizational mortality. Administrative science quarterly pp. 187-218.

Bayramoğlu, G., 2016 Karmaşiklik paradigmasi işiğinda örgüt teorilerinin yeniden değerlendirilmesi. Selçuk Üniversitesi Sosyal Bilimler Enstitüsü Dergisi pp. 49-63.

Chamberlain, L., 1995 Strange attractors in patterns of family interaction. .

D'aveni, R. A., 2010 Hypercompetition. Simon and Schuster.

Doherty, N. and N. Delener, 2001 Chaos theory: Marketing \& management implications. Journal of Marketing Theory and Practice 9: 66-75.

Economist, E., 2009 Organisational agility: How business can survive and thrive in turbulent times. The Economist pp. 1-27.

Farazmand, A., 2003 Chaos and transformation theories: A theoretical analysis with implications for organization theory and public management. Public Organization Review 3: 339-372.

Fitzgerald, L. A. and F. M. van Eijnatten, 2002 Reflections: Chaos in organizational change. Journal of Organizational Change Management .

Gilad, B., 2003 Early warning: Using competitive intelligence to anticipate market shifts, control risk, and create powerful strategies. AMACOM Div American Mgmt Assn.

Gleick, J., 1997 Kaos: Yeni bir bilim teorisi, çev. Fikret Üçkan, TÜBİTAK, Ankara .

Gleick, J., 2005 Kaos: Yeni bir bilim teorisi, çev. Fikret Üçkan, TÜBİTAK, Ankara .

Grandinetti, R., 2018 Is organizational evolution darwinian and/or lamarckian? International Journal of Organizational Analysis .

Habermas, J. and C. A. Kanat, 1997 Bilgi ve insansal ilgiler. Küyerel Yayınları.

Hancerlioglu, O., 1995 Dört bin yıllık düşünce, sanat ve bilim tarihinin klasik yapıtları üzerine eleştirel inceleme. İstanbul: Remzi Kitabevi .

Hannan, M. T. and J. Freeman, 1977 The population ecology of organizations. American journal of sociology 82: 929-964.

Hannan, M. T. and J. Freeman, 1989 Organizational ecology. Harvard university press.

Heylighen, F., 1999 The growth of structural and functional complexity during evolution. The evolution of complexity 8: 17-44.

Hirt, M., S. Smit, C. Bradley, R. Uhlaner, M. Mysore, et al., 2020 Getting ahead of the next stage of the coronavirus crisis. McKinsey \& Company 4.

Holmes, P., 1995 The essence of chaos (en lorenz). Siam Review 37: $129-131$.
Kotler, P. and J. A. Caslione, 2009 Kaos yönetimi: Çalkantılar çağında yönetim ve pazarlama (çev. kıvanç dündar). İstanbul: Optimist Yayınları pp. 12-58.

Lartey, F. M. et al., 2020 Chaos, complexity, and contingency theories: a comparative analysis and application to the 21st century organization. Journal of Business Administration Research 9: 44-51.

Leblebici, D. N., 2004 Örgüt-çevre ilişkisinde yeni perspektif arayişi: Dinamik örgütsel çevre ve örgütsel doku. Hacettepe Üniversitesi İktisadi ve İdari Bilimler Fakültesi Dergisi 22: 285-307.

Levy, D., 1994 Chaos theory and strategy: Theory, application, and managerial implications. Strategic management journal 15: 167-178.

Lorenz, E. N., 1963 Deterministic nonperiodic flow. Journal of atmospheric sciences 20: 130-141.

Loye, D. and R. Eisler, 1987 Chaos and transformation: Implications of nonequilibrium theory for social science and society. Behavioral science 32: 53-65.

Mannermaa, M., 2009 Globalization and information society-increasing complexity and potential chaos. Global Transformations and World Futures-II p. 88.

Mayr, E., 1972 Lamarck revisited. Journal of the History of Biology pp. 55-94.

Mitchell, W. M., 1999 Complexity. the emerging science at the edge of order and chaos, 1992.

Moran, G., 2018 Chaos theory and psychoanalysis: The fluidic nature of the mind. Routledge.

Poincaré, H. and F. Maitland, 2003 Science and method. Courier Corporation.

Porth, S. J. and J. McCall, 2001 Contemporary management theories and catholic social teaching. Review of Business 22: 8-15.

Prakash, C., M. Besiou, P. Charan, and S. Gupta, 2020 Organization theory in humanitarian operations: a review and suggested research agenda. Journal of Humanitarian Logistics and Supply Chain Management .

Rockier, M. J., 1991 Thinking about chaos: Non-quantitative approaches to teacher education. Action in Teacher Education 12: $56-62$.

Simard, M., M. Aubry, and D. Laberge, 2018 The utopia of order versus chaos: A conceptual framework for governance, organizational design and governmentality in projects. International journal of project management 36: 460-473.

Stacey, R. D., D. Griffin, and P. Shaw, 2000 Complexity and management: Fad or radical challenge to systems thinking?. Psychology Press.

Thietart, R.-A. and B. Forgues, 1995 Chaos theory and organization. Organization science 6: 19-31.

van Eijnatten, F. M., 2004 Chaordic systems thinking: Some suggestions for a complexity framework to inform a learning organization. The Learning Organization .

van Eijnatten, F. M. and G. D. Putnik, 2004 Chaos, complexity, learning, and the learning organization: Towards a chaordic enterprise. The Learning Organization .

Zakaria, F., 2013 The rise of the rest. In Debating a Post-American World, pp. 42-51, Routledge.

How to cite this article: Arıcıoğlu, M. A. and Berk, O. N. A Comparative Proposal on Learning the Chaos to Understand the Environment. Chaos Theory and Applications, 4(1), 19-25, 2022. 